\title{
Pelatihan Pembuatan Sabun Cair di SMP dan SMA Islam Ponpes Abu Abdillah Gunungsari untuk Meningkatkan Kompetensi dan Kecakapan Hidup Santri
}

\author{
Hendrawani ${ }^{\star}$, Yusran Khery, Dahlia Rosma Indah, Pahriah, Husnul Hatimah \\ Prodi Pendidikan Kimia, FSTT, Universitas Pendidikan Mandalika, JI. Pemuda No. 59A \\ Mataram, 83125, Indonesia \\ Email Korespondensi: hendrawanichemed@gmail.com
}

\section{Diterima: September 2020; Revisi: Oktober 2020; Diterbitkan: November 2020}

\begin{abstract}
Abstrak
Proses pembelajaran kimia yang inovatif, menyenangkan, aplikatif dan berkaitan langsung dengan real life, dan memfasilitasi kebutuhan life skill yang dapat bernilai wirausaha berupa pelatihan langsung manipulasi bahan-bahan kimia untuk kebutuhan sehari-hari seperti sabun cair di sekolah masih jarang dilakukan khususnya di sekolah swasta. Kegiatan pengabdian kepada masyarakat ini bertujuan untuk melatih santri dalam pembuatan sabun dan pewangi pakaian sebagai upaya pengenalan kimia di sekolah dan pembekalan lifeskill bagi santri. Kegiatan ini diharapkan dapat bermanfaat bagi santri dan mendorong minat dalam mempelajari kimia dan mendorong terbentuknya usaha baru untuk wadah berwirausaha bagi santri. Metode pelaksanaan PKM transfer of knowledge dan technology degan langkah-langkah kegitan 1) persiapan, 2) pelaksanaan, dan 3) evaluasi. Hasil kegitan antara lain 1) mitra dapat memahmi dengan baik tentang prosedur pembuatan sabun cair, 2) terbentuknya keterampilan mitra dalam mebuat produk berupa sabun cair. Kegitan pendampingan perlu dilakukan secara berkelanjutan agar mitra dapat berinovasi dalam pembuatan produk-produk yang dilatih.
\end{abstract}

Kata Kunci: Kompetensi; kecakapan hidup; Sabun cair

\section{Liquid Soap Making Training in Islamic Junior and Senior High School Abu Abdillah Gunungsari Islamic Boarding School to Improve the Competence and Life Skills of Santri}

\begin{abstract}
The learning process for chemistry that is innovative, fun, applicable and directly related to real life, and facilitates the needs of life skills that can be entrepreneurial in the form of direct training on the manipulation of chemicals for daily needs such as liquid soap in schools is still rarely done, especially in private schools. This community service activity aims to train students in making soap and clothing fragrances as an effort to introduce chemistry in schools and provide lifeskills for students. This activity is expected to be useful for students and encourage interest in studying chemistry and encourage the formation of new businesses as a forum for entrepreneurship for students. The method of implementing PKM is transfer of knowledge and technology with activity steps 1) preparation, 2) implementation, and 3) evaluation. The results of activities include 1) partners can understand well about the procedure for making liquid soap, 2) partners' skills are formed in making products in the form of liquid soap. Assistance activities need to be carried out on an ongoing basis so that partners can innovate in the manufacture of trained products.
\end{abstract}

Keywords: Competence; life skills; liquid soap

How to Cite: Hendrawani, H., Khery, Y., Indah, D., Pahriah, P., \& Hatimah, H. (2020). Pelatihan Pembuatan Sabun Cair di SMP dan SMA Islam Ponpes Abu Abdillah Gunungsari untuk Meningkatkan Kompetensi dan Kecakapan Hidup Santri. Lumbung Inovasi: Jurnal Pengabdian kepada Masyarakat, 5(2), 65-70. doi:https://doi.org/10.36312/linov.v5i2.466 


\section{PENDAHULUAN}

Pondok pesantren menjadi salah satu lembaga pendidikan yang dituju oleh masyarakat sebagai tempat anak-anak menimba ilmu pengetahuan. Pesantren berikhtiar meletakkan visi dan kiprahnya dalam kerangka pengabdian sosial yang pada mulanya ditekankan kepada pembentukan moral keagamaan dan kemudian dikembangkan kepada rintisan-rintisan pengembangan yang lebih sistematis dan terpadu (A'la, 2006).

Pesantren terlibat aktif dalam pengkajian keagamaan dan pola-pola sejenis seperti lembaga pendidikan yang dikembangkan masyarakat luas. tahap perkembangan berikutnya, pesantren menjadi bagian dari sistem pendidikan nasional yang dinilai memiliki kontribusi yang besar terhadap pembangunan sumber daya manusia. Pembagunan sumber daya manusia yang dilakukan oleh pondok pesantren lebih mengarah pada sisi pembentukan pribadi santri seperti budi pekerti. Membangun SDM tidaklah cukup dengan membentuk budi pekerti saja, melainkan diperlukan pula berbagai pengetahuan dan ketrampilan (skill) yang selama ini masih kurang mampu dipenuhi oleh pondok pesantren, karena berbagai faktor seperti masih tertutupnya pola pikir pimpinan pondok untuk menerima perkembangan dan kekurangan sarana prasaran (Saepudin, 2016).

Pendidikan yang beroreintasi pada kecakapan hidup sangat dibutuhkan untuk mempersiapkan peserta didik dengan bekal kecakapan hidup, baik untuk menunjang kebutuhan hidup dirinya sendiri maupun sebagai bekal untuk berinteraksi dengan lingkungan. Pendidikan kecakapan hidup adalah pendidikan yang diorientasikan pada kecakapan hidup agar peserta didik berani menghadapi problem kehidupan secara wajar tanpa merasa tertekan, kemudian secara kreatif menemukan serta mampu mengatasinya (Depdiknas, 2002). Melalui pembekalan kecakapan personal, kecakapan sosial, kecakapan akademik dan kecakapan vokasional yang berjalan secara sinergis serta bersifat holistik.

Kecakapan hidup atau life skill disekolah dapat diajarkan melalui matapelajaran IPA salah salah satunya adalah pelajaran kimia. Kimia adalah cabang dari ilmu fisik yang mempelajari tentang susunan, struktur, sifat, dan perubahan materi. IImu kimia meliputi topiktopik seperti sifat-sifat atom, cara atom membentuk ikatan kimia untuk menghasilkan senyawa kimia, interaksi zat-zat melalui gaya antarmolekul yang menghasilkan sifat-sifat umum dari materi, dan interaksi antar zat melalui reaksi kimia untuk membentuk zatzat yang berbeda (Wikipedia, 2019). Pembelajaran kimia yang kreatif, inovatif, aplikatif dimana siswa diberi pengalaman langsung pada kegiatan manipulatif bahan-bahan kimia yang dapat mendorong minat belajar siswa dan membekali siswa keahlian untuk kecakapan hidup (life skill). kimia dianggap pelajaraan yang sulit sehingga dibutuhkan proses pembelajaran yang menyenangkan agar siswa tidak cepat bosan.

Proses pembelajaran kimia seringkali fokus pada pemahaman konsep dan hapalan rumus tanpa ada kegiatan-kegiatan aplikatif yang berhubungan dengan kehidupan seharihari. Hal ini dapat menyebabkan rendahnya minat belajar siswa dan mendukung persepsi siswa terhadap kimia yang tidak relevan dengan kehidupan nyata dan sehari-hari siswa (Broman et al., 2011). Keterbatasan sarana dan prasarana berupa laboratorium dan juga keahlian guru pengampu mata pelajaran sering menjadi kendala dalam pembelajaran praktikum. Masalah seperti ini salah satunya terjadi di SMA Islam Abu Abdillah, Gunungsari. Hal tersebut disebabkan oleh pengalaman guru dan sarana yang masih kurang memadai, seperti tidak tersedianya laboratorium. Padahal, gerakan pembelajaran yang menyenangkan sudah merupakan agenda nasional pendidikan Indonesia. Salah satu hasil yang diharapkan dari gerakan tersebut adalah meningkatnya kualitas pendidikan melalui suasana sekolah dan pembelajaran yang menyenangkan (Kemdikbud, 2015).

Gambaran umum kondisidi pondok pesanter di SMA Islam Abu Abdillah berdampak pada kompetesi dan kecakapan hidup yang dimiliki santri santri. Proses pembelajaran yang hanya menekankan pada kemampuan kognitif tanpa diimbagi dengan kemampuan psikomorik sebagai pendorong kecakapan hidup.

Pembelajaran kimia di SMA diharapkan dapat menjembatani pemahaman akan fenomena alam dan membekali siswa kompetensi untuk mencipta bahan-bahan sederhana yang dapat bermanfaat khususnya bagi kehidupan siswa, sehingga siswa dapat merasakan manfaat dalam belajar kimia. Oleh karena itu, dalam kegiatan pembelajaran kimia diperlukan bentuk kegiatan lain selain ceramah, yakni berupa pembekalan kecakapan hidup sederhana 
bagi siswa sebagai bentuk pembelakalan vocational skill (Umam, 2018). Salah satunya adalah melalui kegiatan pelatihan pembuatan sabun dan pewangi pakaian yang merupakan bentuk aplikatif dari pembelajaran kimia (Tanjung, 2018). Kegiatan ini diharapkan dapat menjadi model pembelajaran kimia kontekstual yang dapat mendorong minat belajar siswa dan sikap positif siswa terhadap ilmu kimia (Kennepohl, 2007), dan yang terpenting adalah menjadi sarana pembekalan untuk membina kecakapan hidup santri khususnya di Ponpes Abu Abdillah, Gunungsari.

Berdasarkan uraian di atas tujuan dari kegiatan Pengabdian pada masyarakat ini adalah melatih santri dalam pembuatan sabun cair sebagai upaya pengenalan kimia di sekolah dan pembekalan life skill bagi santri. Kegiatan ini diharapkan dapat bermanfaat bagi santri dan mendorong minat dalam mempelajari kimia dan mendorong terbentuknya usaha baru untuk wadah berwirausaha bagi santri

\section{METODE}

Kegiatan Pengabdian pada Masyarakat dilaksanakan dengan Metode transfer of knowledge dan transfer technology dengan langkah-langkah kegitan 1) persiapan, 2) pelaksanaan, dan 3) evaluasi. Kegitaan diikuti oleh 36 orang santri Ponpes SMA Islam Abu Abdillah Gunungsari. Langkah-langkah kegiatan sebagai berikut

a) Melakukan survey lokasi dan sosialisasi kegiatan Pengabdian oleh Tim.

b) Melakukan sosialisasi pelatihan pembuatan sabun dan pewangi pakaian kepada pihak sekolah dan beberapa komponen civitas akademik lingkungan ponpes Abu Abdillah Gunungsari.

c) Memberikan materi pentingnya kemandirian dan kecakapan hidup bagi santri, sosialisasi kegiatan Chemopreneurship goes to school oleh program studi S1 Pendidikan Kimia Universitas Pendidikan Mandalika dan pemaparan langkah kegiatan pembuatan sabun dan pewangi.

d) Melakukan pelatihan dan pembimbingan praktek pembuatan sabun dan pewangi pakaian kepada siswa SMA Islam Ponpes Abu Abdillah.

e) Evalusi untuk mengetahui peningkatan pemahaman dan kecakapan hidup santri.

\section{HASIL DAN PEMBAHASAN}

Kegiatan Pelatihan pembuatan sabun cair dan pewangi di Pondok Pesantren Abu Abdillah ini berlangsung dalam 2 sesi. Sesi 1) kegiatan pembekalan materi pentingnya kemandirian dan kecakapan hidup santri serta penjelasan tentang sabun cair, cara pembuatan dan peluang produksi dan pemasarannya, dan sesi 2) kedua dilaksanakan pelatihan dan pembimbingan praktek pembuatan sabun.

\section{Hasil analisis peningkatan pemahaman siswa}

Pemahaman santri tentang materi yang disampaikan dievaluasi menggunakan isntrumen tes. Instrumen diberikan dua kali yakni sebelum memulai pembekalan materi dan sesudahnya, hal tersebut untuk mengetahui peningkatan pemahaman siswa. Adapun hasil analisis disajikan dalam bentuk diagram pada Gambar 1 berikut.

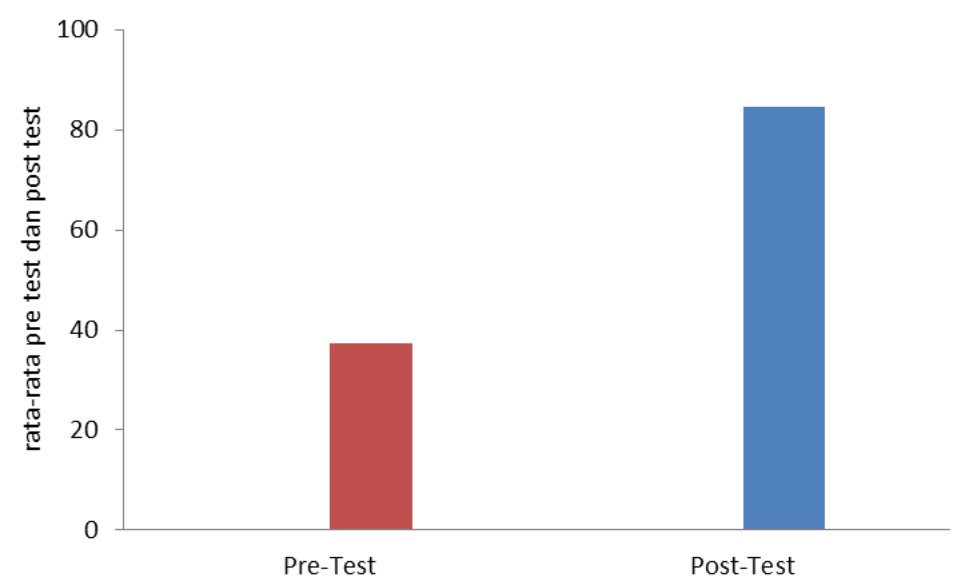

Gambar 1. Diagram analisis Pre test dan Post test 
Diagram di atas (Gambar 1) menunjukkan bahwa ada peningkatan pemahaman siswa tentang materi yang disajikan dari 37.4 menjadi 84.6 dengan rata-rata peningkatan sebesar 46.7. Pemahaman siswa tentang materi pentingnya kemandirian dan kecakapan hidup akan dapat membatu memotivasi siswa untuk mandiri dan membuat inovasi-inovasi untuk menunjang kehidupan sehari-hari. Perilaku mandiri merupakan fundamen dasar bagi seseorang dalam meningkatkan kualitas kerja (pekerjaannya) (Baruwadi, 2012). Kemandirian sebagai kepribadian atau sikap mental yang harus dimiliki oleh setiap orang yang di dalamnya terkandung unsur-unsur dengan watak-watak yang ada di dalamnya perlu dikembangkan agar tumbuh menyatu dalam setiap gerak kehidupan manusia (Darwis, 1993).

Setelah pembekalan tentang pentingnya kemandirian dan Life skin dilanjutkan pembekalan tentang mekanisme pembutaan sabun cair. Metode pembekalan dengan ceramah, diskusi, tanya jawab dan demostrasi. Pengunaan multi metode berdampak pada peningkatan pemahaman peserta tentang materi yang disampaiakan. Penggunaan multi metode dalam kegiatan penyuluhan dapat memudahkan peserta memahami dan menyerap materi dengan baik, selian itu proses peyuluhan lebih interaktif dan menyenangkan (Hunaepi et al., 2017).

\section{Pedampingan Pembuatan produk}

Pembuatan produk dilakukan setelah peserta diberikan pembekalan dan dinyatakan memahami tentang bahan-bahan yang digunakan serta mekanisme pembuatan secara teori. Proses pembuatan dilakukan dengan pendampingan dari tim PKM. Bahan-bahan yang digunakan disajikan dalam dalam Tabel 1.

Tabel 1. Bahan-bahan pembuatan sabun cair (Hunaepi et al., 2017)

\begin{tabular}{lll}
\hline No & Nama Bahan & Jumlah \\
\hline 1 & Texafon & $1 \mathrm{~kg}$ \\
2 & Sodium Sulfat & $350 \mathrm{gram}$ \\
3 & Metail & $150 \mathrm{ml}$ \\
4 & Glucotain & $100 \mathrm{ml}$ \\
5 & Pewangi & $100 \mathrm{ml}$ \\
6 & Pewarna & $100 \mathrm{ml}$ \\
7 & Labs atau 1 genggam soda ash & $250 \mathrm{ml}$ \\
8 & Air (menyesuikan dengan kebutuhan) & \\
\hline
\end{tabular}

Setelah bahan-bahan yang dibutuhkan disiapkan selanjutnya pembuatan sambun cair dengan langkah-langkah pembutaan sebagai berikut.

1. $1 \mathrm{~kg}$ texafon ditambahkan 350 gram sodium sulfat kemudian tambahkan air dan aduk hingga membentuk jely, pengadukan dilakukan secara terus menerus sambil menambahkan air sampai encer, setelah encer tambahkan metain $150 \mathrm{ml}$, kemudian tambahkan air lagi.

2. Siapkan $100 \mathrm{ml}$ glucotain tambahkan pewangi $100 \mathrm{ml}$ dan pewarna $100 \mathrm{ml}$ ketiga bahan yang telah tercampur di aduk agar dapat bercampur secara merata (wadah terpisah) setelah ketiga bahan tercampur dengan merata lalu campurkan dengan deterjen yang telah dibuat pada langkah awal, pencampuran di aduk sampai menyatu dengan deterjen.

3. Pada wadah yang berbeda siapkan $250 \mathrm{ml}$ labs +40 gram atau satu gemgam soda ash, setelah jadi, lalu ditambakan ke deterjen yang dibuat dan diaduk terus sambil ditambahkan air hingga 15 liter

Proses pembutan dilakukan oleh masing-masing kelompok yang dibimbing oleh tim pengabdian yang dibantu oleh 3 orang asisten (mahasiswa program studi kimia universitas pendidikan mandalika) adapun proses pendampingan pembutan disajikan pada Gambar 2 berikut. 




Gambar 2. Kegiatan proses pembimbingan pembuatan sabun cair

Respon peserta dengan adanya kegitan pelatihan sangat baik, dengan indikator peserta atusias dan semangat mengikuti setiap sesi pelatihan selain itu setiap peserta dapat mengetahui dan memahmi formula setiap bahan yang digunakan serta langkah-langkah pembuatan prosuk berupa sabun dan pewangi pakaian.

\section{Evalusi dan tidak lanjut}

Evaluasi dilakukan dengan cara wawancara lansung pada setiap kegiatan kepada peserta. Evaluasi bertujuan untuk mengetahui tanggapan peserta tetang kegiatan yang dilakukan. Aspek yang ditinjau antara lain.

1. Penyajian materi, hasil penyajian materi yang diberikan pada sesi 1 berdasarkan analisis respon peserta adalah sangat baik. $90 \%$ peserta memberikan respon bahwa penyajian materi sangat baik, dan ada tambahan sangat bermanfaat untuk membuka wawasan peserta tentang ilmu kimia yang ternyata bermanfaat dalam kehidupan sehari-hari.

2. Kegiatan Pembimbingan. Dalam kegiatan pembimbingan membuat sabun cair dan pewangi, peserta memberikan respon sangat baik (95\% memberikan skor sangat baik). Komentar beberapa peserta diantaranya, bahwa pembimbing atau tutor sangat telaten dan sabar serta komunikatif dalam membimbing peserta dalam kegiatan praktek.

3. Kebermanfaatan kegiatan. Dari sisi kebermanfaatan kegiatan, para peserta menunjukkan respon sangat baik ( $90 \%$ menjawab sangat baik). Kegiatan ini sangat bermanfaat untuk melatih kecakapan hidup santri terutama dalam membuat produk dan memasarkannya. Produk yang dihasilkan adalah produk sehari-hari yang sangat lekat dengan kehidupan sehari-hari, yakni sabun dan pewangi.

4. Penguasaan proses pembuatan sabun cair dan pewangi. Dari sisi penguasaan proses pembuatan sabun, mengenal bahan-bahan yang digunakan dan cara kerja yang ditunjukkan oleh peserta sudah baik. Sebagian besar dari peserta tidak takut untuk mencoba memanipulasi bahan-bahan yang disediakan dan bekerja sesuai cara kerja yang diberikan kepada setiap kelompok dan dibimbing oleh tutor.

5. Keberhasilan produk. Produk yang dihasilkan telah dapat berguna sebagai sabun cair dan pewangi dan berhasil sesuai rencana.

\section{KESIMPULAN}

Kegiatan pengabdian yang telah dilaksanakan dapat dikatagorikan berhasil dengan baik hal tersebut dilihat dari respon peserta kegiatan pada setiap sesi menunjukkan kemajuan yang baik, kemampuan dan pemahaman peserta mengalami peningkatan mencapai rata-rata 46.7. keterampilan peserta dalam pembuatan produk sangat baik hal tersebut ditandai dengan berhasilnya peserta membat produk dengan standar yang ditetapkan tim pengabdian. 


\section{REKOMENDASI}

Kegian pendampingan perlu terus dilakukan agar mitra dapat membuat produk secara mandiri, selain itu perlu ada inovasi-inovasi varian pada produk yang telah dibuat seperti aroma, warna, pengemasan dan pelabelan.

\section{UCAPAN TERIMA KASIH}

Ucapan terima kasih kami sampaikan kepada mahasiswa pendidikan kimia, Undikma dan HMPSP Kimia serta staff Lab Kimia Undikma yang telah banyak membantu pelaksanaan pengabdian ini dan kepada kepala Yayasan Ponpes Abu Abdillah dan para santri yang telah bekerja sama dengan kami dalam pelaksanaan pengabdian terutama ditujukan kepada pemberi dana penelitian atau donatur. Ucapan terima kasih dapat juga disampaikan kepada pihak-pihak yang membantu pelaksanaan penelitian.

\section{DAFTAR PUSTAKA}

A'la, A. (2006). Pembaruan Pesantren, Cetakan I. Pustaka Pesantren.

Baruwadi, D. (2012). Penyelenggaraan Pendidikan Kecakapan Hidup Dalam Peningkatan Kemandirian Pemuda. Jurnal Pendidikan Luar Sekolah, 8(1), Article 1. https://ejournal.upi.edu/index.php/pls/article/view/1011

Broman, K., Ekborg, M., \& Johnels, D. (2011). Chemistry in crisis? Perspectives on teaching and learning chemistry in Swedish upper secondary schools. Nordic Studies in Science Education, 7(1), 43-53. https://doi.org/10.5617/nordina.245

Darwis, R. (1993). Transformasi Nilai-nilai Tradisi Kekeluargaan dalam Pendidikan Kewirausahaan (Studi Kasus Pengembangan SDM dalam Pengelolaan Rumah Makan Minang [Disertation]. PPS IKIP Bandung.

Depdiknas. (2002). Kecakapan Hidup life Skill Melalui Pendekatan Pendidikan Berbasis Luas. SIC.

Hunaepi, H., Samsuri, T., Firdaus, L., Mirawati, B., Ahmadi, A., Muhali, M., Asy'ari, M., \& Azmi, I. (2017). Pemberdayaan Ibu-lbu Pkk Melalui Pelatihan Produksi Deterjen Cair Di Desa Sukaraja Lombok Tengah. Lumbung Inovasi: Jurnal Pengabdian kepada Masyarakat, 2(1), 65-67. https://doi.org/10.36312/linov.v2i1.416

Kemdikbud. (2015). Pedoman Gerakan Sekolah Sehat, Aman, Ramah Anak, dan Menyenangkan. Kemdikbud Dirjen Dikdas.

Kennepohl, D. (2007). Using home-laboratory kits to teach general chemistry. Chem. Educ. Res. Pract., 8(3), 337-346. https://doi.org/10.1039/B7RP90008B

Saepudin, J. (2016). PENDIDIKAN KECAKAPAN HIDUP DI PESANTREN DARUL HIKAM BANJARAN BANDUNG. EDUKASI: Jurnal Penelitian Pendidikan Agama Dan Keagamaan, 14(1). https://doi.org/10.32729/edukasi.v14i1.5

Tanjung, D. A. (2018). Pelatihan Pembuatan Sabun Cair dan Shampo Pencuci Mobil. JURNAL PRODIKMAS Hasil Pengabdian Kepada Masyarakat, 2(1), Article 1. https://doi.org/10.30596/jp.v2i1.1761

Umam, A. K. (2018). Perberdayaan Santri Melalui Pendidikan Kecakapan Hidup. Tarbawiyah: Jurnal Ilmiah Pendidikan, 1(01), 163-179. https://doi.org/10.32332/tarbawiyah.v1i01.1015

Wikipedia. (2019). Kimia. In Wikipedia bahasa Indonesia, ensiklopedia bebas. https://id. wikipedia.org/w/index.php?title=Kimia\&oldid=18027444 